\title{
PROSPECTS FOR THE DEVELOPMENT OF MOTOR THIRD PARTY LIABILITY INSURANCE ON THE BULGARIAN INSURANCE MARKET
}

\author{
T. Andreeva* \\ Finance Account Faculty, Finance Department, University of National and World Economy, \\ Sofia, Bulgaria
}

\begin{abstract}
The aim of the report is to examine the current and important for the society issues concerning one of the most widespread insurance products - Motor Third Party Liability Insurance. The report examines the use of Motor Third Party Liability insurance on our insurance market. Specific studies have been made on the actual presence of the insurance in the local market and the motor insurance in the general insurance portfolio at European level. The problems and trends in the application and the proposed "Bonus-Malus" system are considered. Further considerations regarding the Bonus-Malus system have been made, taking into account the role of the system for fair payment of insurance premiums. The positive experience of the European insurance market is also reported. The report also focuses on other regulatory and other factors determining the market development. Quantitative methods of analysis and evaluation are used.
\end{abstract}

Key words: insurance market, Bonus-malus system, insurance premium, insurance reserves, premium income, insurance indemnities

JEL: G2

\section{INTRODUCTION}

The development of Motor Third Party Liability (MTPL) insurance is always an up-todate topic given the public importance and problematic nature of the insurance. Its' importance is determined by its' mandatory nature and social component. The insurance ensures the protection of the interests of the suffered third parties.

Its' high market share also determines its importance for the financial stability of insurance companies. Last but not least, the valuation of assets and the requirement for solvency in the non-banking sector is part of the requirements for Bulgaria for approvale in the euro zone (ERM2).

A key issue in the insurance is the risk management, as the development of the risk

\footnotetext{
*Correspondence to: Chief assistant Tzvetelina Andreeva, Ph.D, Finance Department, Finance account faculty, University of national and world economy, Sofia, 89B, bul. Vitosha, Millenium center, Sofia, Bulgaria, mobile: +359888246624, tzvetelina.andreeva@gmail.com
}

with this insurance is often unfavorable to insurers. Negative result of the insurance on our market was confirmed with a report of the Financial Supervision Commission (FSC) from 2018.

The challenges for writing this report are first the treatment of the MTPL insurance essentials with an emphasis on contemporary features and current practical issues. Second, the reasons and arguments put forward concerning the implementation of the Bonus-Malus system by the obligatory Motor Third Party Liability insurance.

\section{Characteristic of the insurance}

On the Bulgarian insurance market Motor Third Party Liability insurance has a significant share of about $40 \%$ in the non-life insurance portfolio. The insurance is compulsory under the Insurance Code and under the signing of insurance contract, in the form of a policy with requisites and under insurance conditions defined in the legislation. With each MTPL policy is issued with a green card certificate and a sticker, which are issued 
by the National Bureau of Bulgarian insurers. The period of validity of the certificate and the sticker is usually one year, from the beginning of the coverage until the end of the period for which a sucequent installment from the insurance premium is paid or till the end of the insurance contract with a lump sum paid insurance premium.

Compulsory Motor Third Party Liability insurance covers insured liability for material and non-material harm to third parties:

- Non-material and material harm resulting from bodily injury or death;

- Damages to third party property;

- Lost benefits that are a direct and immediate result of the disability/demage;

- Reasonably incurred costs in connection with the claim, including court costs awarded to the insured;

- Interests.

The minimum limits of liability by the insurance are:

- For non-material and material harm resulting from bodily injury or death:

- 2100000 BGN for each event by one injured person;

- 10420000 BGN for each event by two and more injured persons;

- For damages to propery - 2100000 BGN for each event.

The territory of validity of the insurance includes:

- Republic of Bugaria in accordance with the Bulgarian law;

- EU member state in accordance with the state law;

- A third country when damage has been caused to persons from a Member State when traveling between the territories of two Member States and provided there is no national insurance bureau responsible.

Motor Third Party Liability insurance Premiums must be sufficient, calculated on reasonable actuarial assumptions, to ensure that all insurers' liabilities to third parties for guilty damages to the third parties by the insured are fulfilled, including allowing the formation of sufficient technical reserves as follows:

- Safety fund;

- Reserve for outstanding losses;

- Unpaid premium reserve;

- Reserve for non-terminated risks;

- Reserve for bonuses and discounts;
- Other reserves, approver by the FSC or formed on its prescription.

The formed reserves are part of the risk premium or the gross premium of the insurance. For its calculation, the risk should be assessed. The assessment is made on the basis of the accumulated statistics for the aggregate for which the risk for the past period is calculated. Data on paid claims is taken on the basis of which the net premium is set. To the net premium are added the insurer's expenses, Guarantee and Security Fund costs and other, resulting in the gross premium. Risk groups and sub-groups are formed for a more thorough and accurate risk assessment and the insurance premium is determined for them. Risk groups and sub-groups are formed for a more thorough and accurate risk assessment and the insurance premium is determined for them. Gross premiums for each risk group are combined and form the tariff for the respective group.

For the purpose of risk management, it is essential to calculate adequate insurance premiums, to allocate sufficient reserves and to develop reinsurance programs.

When there is no MTPL insurance issued or by insolvency of the insurer for securing the payments, the Guarantee Fund and the National Bureau are established. They are compensation bodies that make payments of Bulgarian car insurers. The installments to the fund are mandatory and are included in the insurance price. They are divided into a Guarantee Fund installment from which indemnities for uninsured vehicles are paid and an installment to the Security Fund for payments by insolvency. The Guarantee Fund contribution is updated each year and depends on the Fund's reserves at the end of the period. The contribution for the Security Fund is at the amount of BGN 1.50. for each insured vehicle and has not been updated the last years.

The National Bureau of Bulgarian Motor Insurers represents the Republic of Bulgaria in the Council of Bureaus by participating and assisting in the functioning of the Green Card system and the MTPL insurance in the member states and in the states who signed to the Multilateral Agreement for payment of indemnities and insurance sums to the victims for insurance events abroad. Any insurer licensed to offer obligatory MTPL insurance in the Republic of Bulgaria is obliged to become a member of the National Bureau of Bulgarian 
Motor Insurers before starting to practice the insurance.

Scope and place of insurance on the insurance market

Motor Third Party Liability insurance is mandatory not only under national law. The main framework of rules and the limits of the insurance are laid down in Directive 2009/103 /EC.
The scope of the insurance should be $100 \%$ of all motor vehicles on the territory of the country.

As can be seen from Figure 1 for the period from August 2012 - August 2018 as a result of a number of measures, incl. sanctions in the absence of a policy, termination of registration of the vehicle, etc. the scope rises from $74.89 \%$ to $99 \%$.

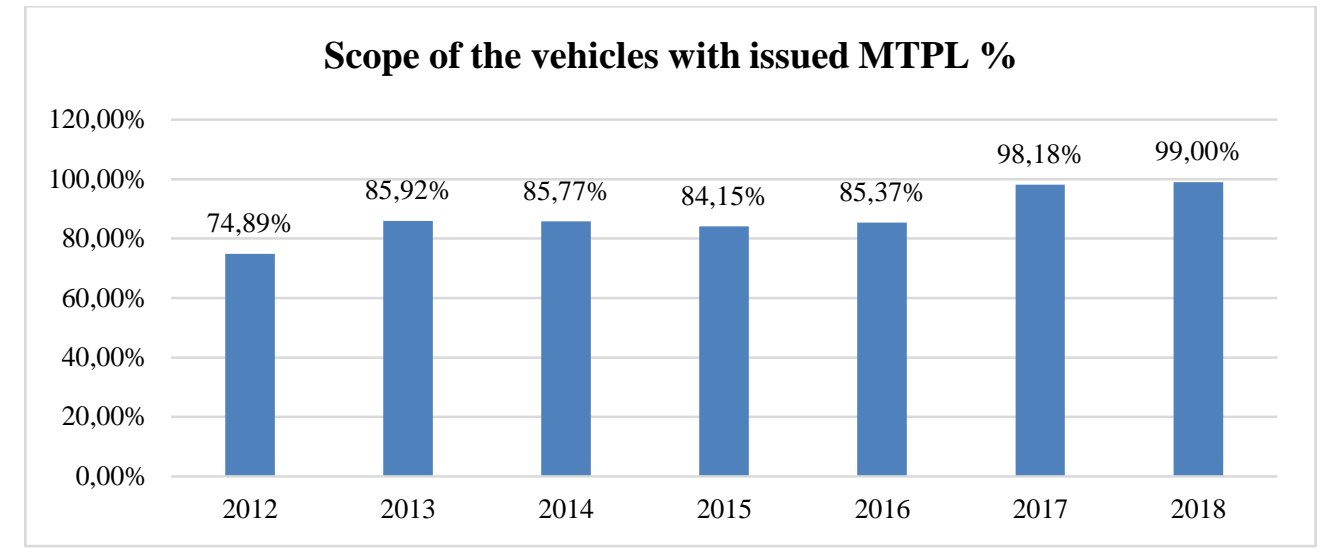

Figure1. Scope of the insurance in Bulgaria

Source: Calculations based on data from the Guaranty fund, provided by the Traffic Police

By August 2018 from 3053143 motor vehicles to be insured, 3022717 have active policies. By comparison for the same period in 2017 from 3050107 active vehicles, 2994
451 have insurance. Figure 2 shows that the number of uninsured vehicles in number of 55656 by August 2017 decreases almost by half in a year and by August 2018 is 30426 .

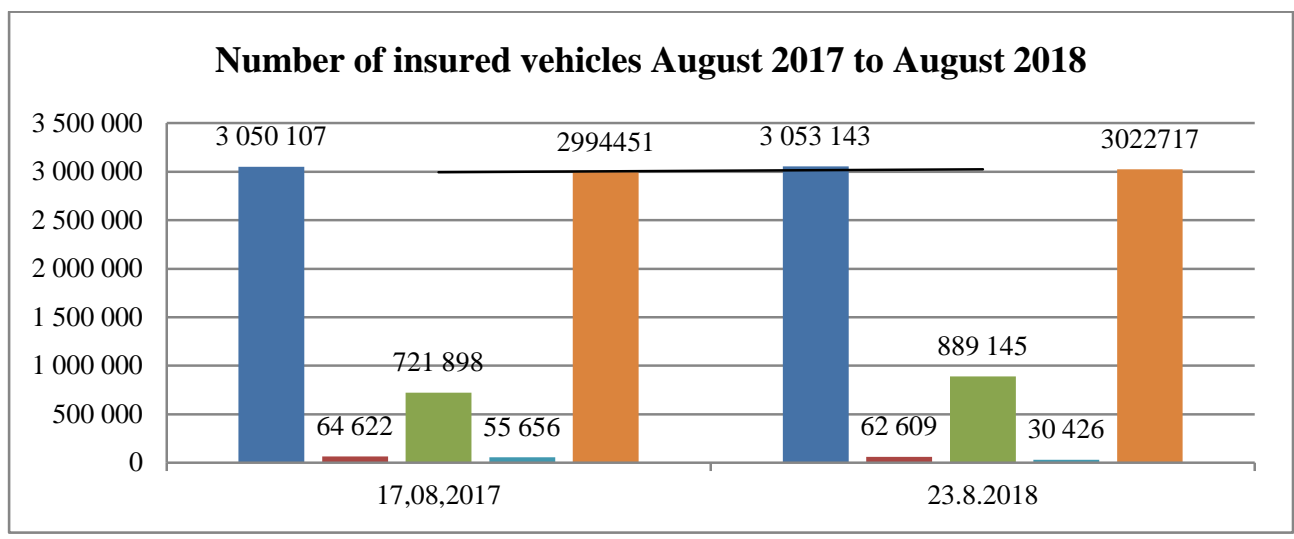

Number of active vehicles

Number of vehicles stopped

Number of terminated

Number of uninsured vehicles

Number of insured vehicles

Figure 2. Comparison of the number of vehicles with issued policy and uninsured vehicles for the period 2018 to 2017

Source: Calculations based on data from the Guaranty fund, provided by the Traffic Police

The share of MTPL insurance on the Bulgarian market is highest compared to other types of insurance and varies from $37 \%$ to $43.81 \%$ by August 2018 (Figure 3). 


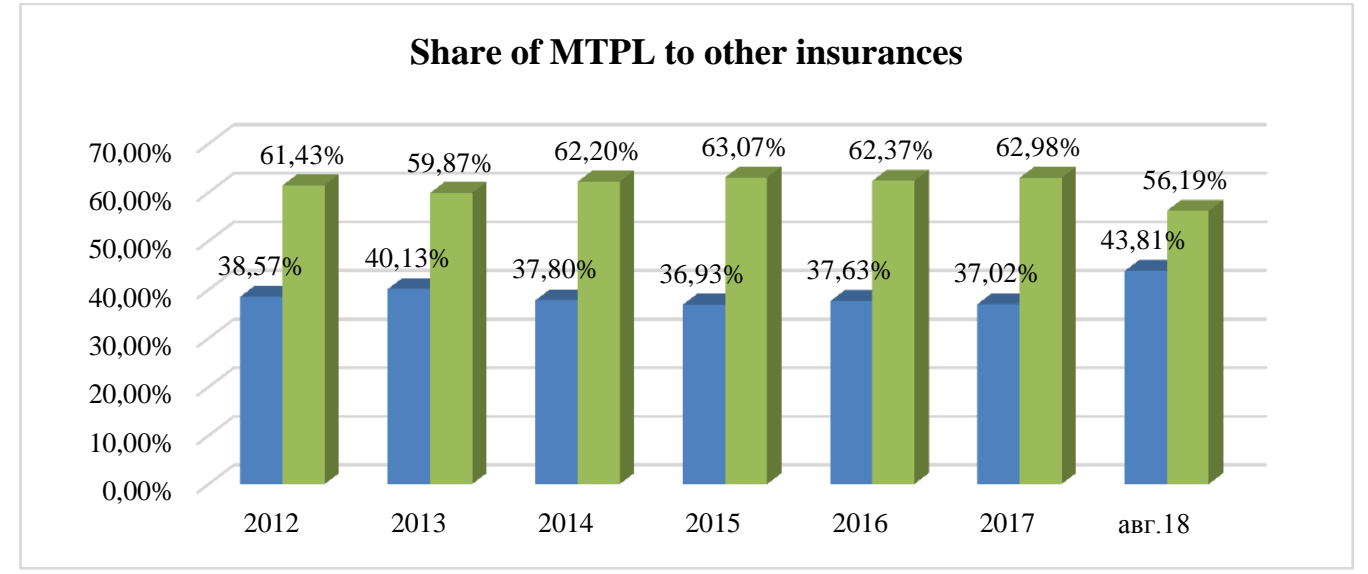

Figure 3. Share of MTPl insurance vs. other insurances in Non-life insurance \% Source: Calculations of the author based on data from FSC

The rising share of the insurance in 2018 is due more to the overall increase in market prices and to a lesser extent to the growth of the insured motor vehicles.

Since 2017 there has been an increase in the prices of the insurance on our market as the increase in 2018 is more serious. The growth of active policies towards the end of October 2018 compared to 2017 is $2.7 \%$, while premium growth after August 2018 is between 30 and $60 \%$ for individual vehicle types compared to 2017.

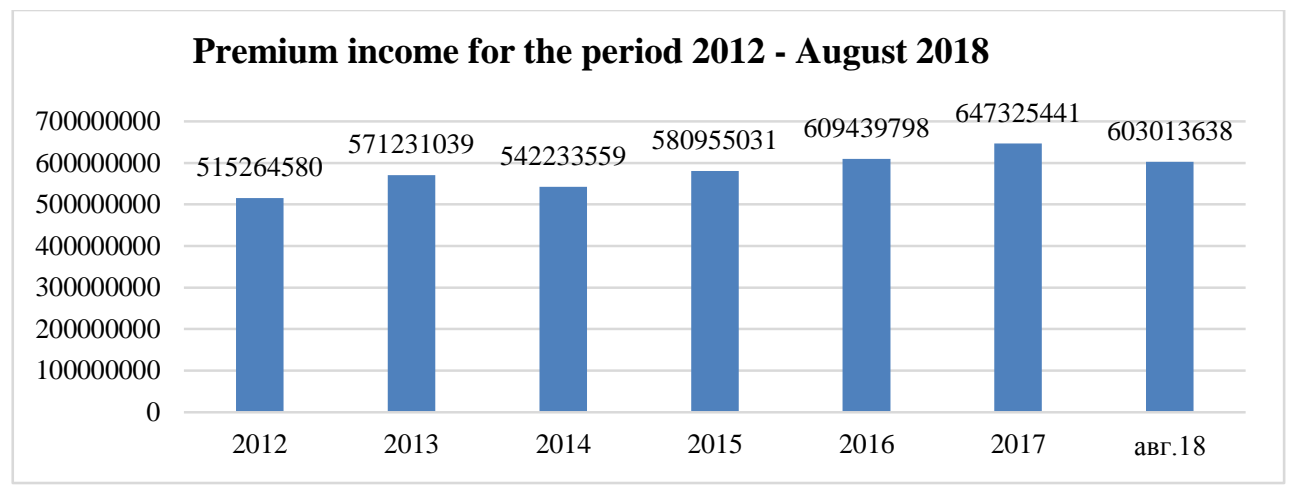

Figure 4. Premium income of MTPL insurance in BGN

Source: Calculations of the author based on data from FSC

The premium income of the insurance (Figure 4) is increasing as by August 2018 it is almost equal to the premium income for the whole 2016. The increase in premium income is mainly the result of a rise in insurance prices, which in turn is the result of changes in the market environment over the past year.

For comparison at European level, motor insurance has the largest share in non-life insurance in 2017. It represents $37 \%$ of nonlife insurance premiums (Figure 5).

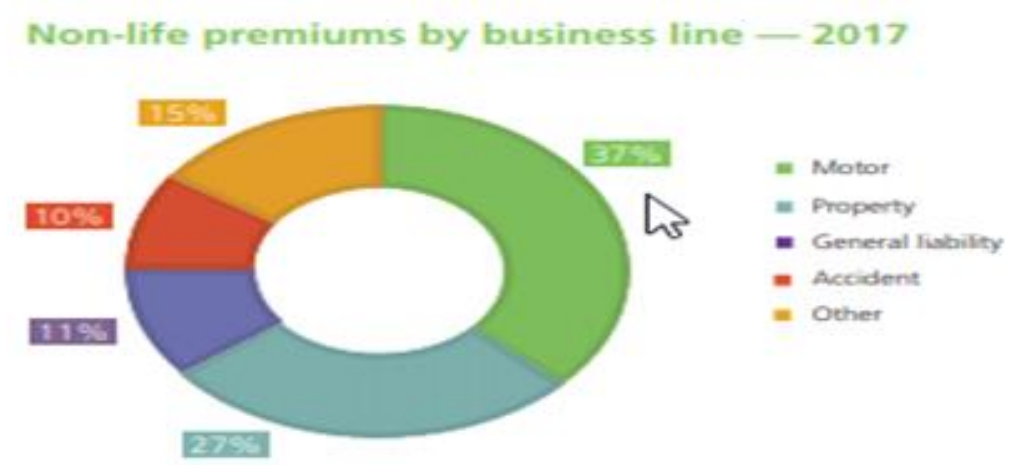

Figure 5. Share of the motor insurance in the non-life insurance portfolio on European level Source: Report European insurance - Key Facts 
The motor insurance premiums rose by $4.2 \%$ in 2017 to 138 billion euro. In 2017, the insurance penetration in non-life insurance slightly increased from $2.23 \%$ to $2.27 \%$, ranging from $0.6 \%$ in Latvia to $3.4 \%$ in the United Kingdom ${ }^{1}$.
The market share of the top 5 insurers (Figure 6) is over $65 \%$ of the total market, with reaching $71.41 \%$ in 2014 and respectively $70.04 \%$ in 2016.

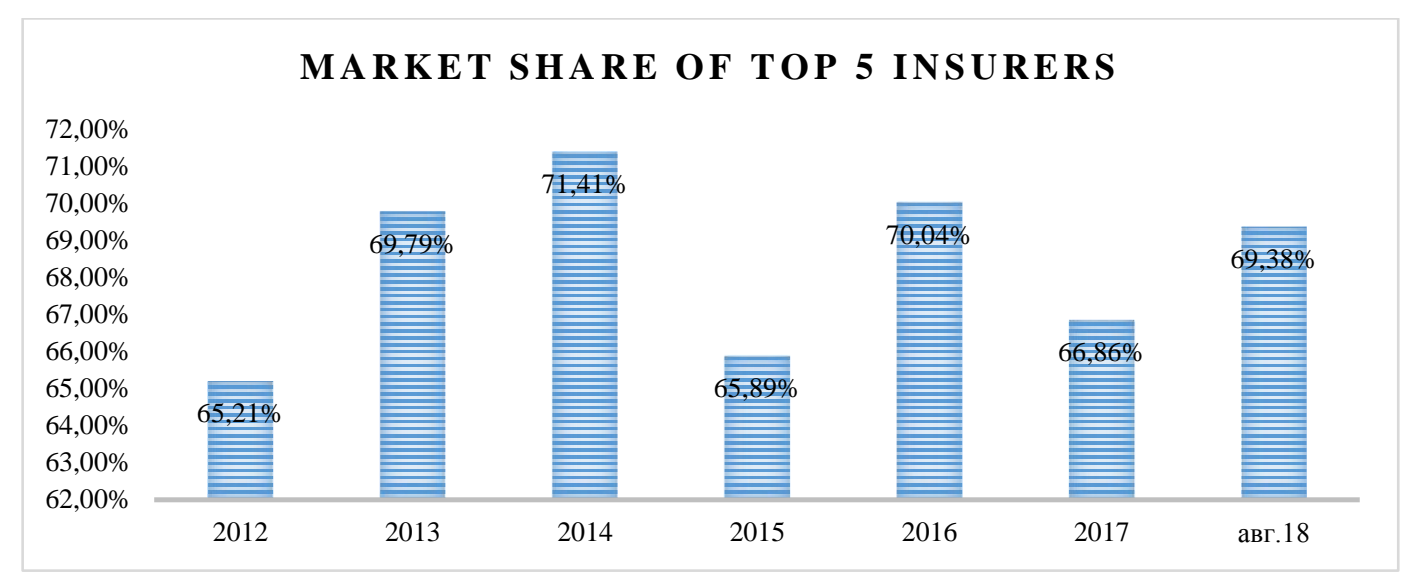

Figure 6. Market share of the first 5 insurers regarding premium income by August 2018 Source: Calculations of the author based on data from FSC

Based on data from FSC the first 3 companies have a market share of almost $50 \%$ of all insured vehicles in 2018.

\section{Development of the market of the insurance} During the period 2013-2017 the average insurance premium for a motor vehicle in Bulgaria was relatively constant within the range of 202 to $209 \mathrm{BGN}$. Premiums were held at these levels due to high competition on the market and unfair practices and behavior of some of the local market participants. Since mid 2018, the average insurance premiums on the market have increased by about $22 \%$ due to a number of factors: negative overall insurance market outcomes officially announced by the Financial Supervision Commission (FSC) report in 2018; the Supreme Court of Cassation's interpretative decision to increase the number of persons eligible for indemnities; bankruptcy of the insurance company "Olympic".

Based on a survey by the Association of Insurers in Bulgaria by the end of 2016, the average price of the insurance is one of the lowest in Europe. Below the price in Bulgaria is only the price in Latvia and Hungary. The highest levels in the period considered are in Italy and Belgium in the amount of over and around $200 \%$ more, followed by Greece and Germany by around $120 \%{ }^{2}$

\footnotetext{
${ }^{1}$ Report European insurance - Key Facts

${ }^{2}$ The Association of Insurers in Bulgaria via data from Insurance Europe
}

On the basis of the calculations made by the FSC for the claims paid and filed for the whole local market, an insufficiency in the Motor Third Party Liability insurance premiums was established. The FSC report concludes that the insurance premiums do not cover the costs, which in itself implies a need to raise the price of the insurance. It should be noted that the calculations made are general for the market and include all risk groups. Or, the results of individual insurers can not be inferred. It can be expected that not all insurers are at a loss provided a balanced portfolio of the insurance and conduction of segmentation policy aimed at low-risk groups.

The insurance reinsurance program on our market is based on an excess loss coverage with Swiss Re, which as a leader of the reinsurance contracts of almost all companies on the market is working in the direction and exerts strong pressure on the market to increase the self-retention of 500,000 euros and continues to raise tariffs on reinsurance contracts, in order for companies to increase their own tariffs. This trend can be expected to continue in the future, due to the negative development of the market damages.

The placement of the Republic of Bulgaria under monitoring by the International Green Card Bureau relates to the conclusion of a general reinsurance contract for the whole market. This leads to an increase in the reinsurance price of companies with a low risk 
portfolio, as reinsurance is part of the insurance premium. The raise of the premium of the reinsurance contracts will inevitably affect the price of the insurance. This, in turn, does not mean a reduction in the price of the insurance for insurers with "bad" portfolio, as it can be assumed that they are currently unable to cover its costs/ payments with the collected premiums, which was the reason that measure to be imposed. For insurers with a low risk portfolio, the increase in the reinsurance contract tariff rate from $4-5 \%$ to $10-12 \%$ will affect the price as the amount of the increased will depend on the market share of each of these insurers.

\section{Bonus-malus system}

In the process of discussion and implementation in Bulgaria is the system "Bonus-Malus" of Motor Third Party Liability insurance on the basis of the set in the Insurance Code. This system is a technique (method, tool, model, scheme) for "discounts and loadings" under certain conditions that have long been known and applied in the insurance industry. The aim of the system is to stimulate "good" and punish "bad" motorists for the sake of fairness in determining insurance premiums - the price of insurance.

In insurance, and in particular in motor insurance, the Bonus-Malus system can be defined as a way of calculating a premium on a policy based on a history of damages that are guiltily caused by the insured driver. This system pursues and is qualified as a tool for defining the so-called "deserved premium" by the insurer. Through it, the premium is individualized according to the history of the guilty damages of the managed vehicle and/ or the damages caused with it to third parties by the insured in a given aggregate. It pursues a fair segmentation of the income from an insurance portfolio (insurance) and improvedment of the insurance results.

Under a variety of forms this pricing system is widely used in motor insurance around the world - particularly by compulsory motor third party liability insurance, as well as y voluntary motor casco insurance and other insurances.

The proposed option for introduction in Bulgaria is based on the history of the vehicle owner and that of the vehicle for the occured accidents and/ or violations, as there is no requirement in the legislation of the Republic of Bulgaria for the Motor Third Party Liability Table 1. Applied rules for Bonus-malus in Bulgaria insurance policy to include nformation about the drivers, which creates preconditions for circumventing the system, as well as transferring ownership to drivers without violations. This does not eliminate the possibility of ownership being transferred to a vehicle of a more favorable Bonus-Malus (BM) rating and to benefit from a lower insurance premium. It is therefore proposed in the case of transfer of ownership of the vehicle, the BM classification to be determined taking into account the history of vehicle claims along with that of the owner and the choice to be the more risky of both. This leads to the need road accidents and/ or violations to be accurately recorded and o be recorded on the vehicle and on the owner of the vehicle and/ or to a third party where this is feasible.

The proposed rules for the Bonus-Malus in Bulgaria are described in Table $\mathbf{1}$ with a comparison with other countries.

The bonus-malus system is a system of rules that defines an insurance premium adjustment based on the individual risk of each driver based on past road traffic offenses and road traffic accidents. The bonus-malus coefficient combines groups of individuals with a similar risk profile. These violations are categorized and include:

- Excess speed depending on the number of kilometers per hour above the allowable, the location and the vehicle;

- Damages caused to property, bodily injuries, serious injuries, death;

- Overtaking, dangerous maneuvers, nonobservance of distance, other risk violations;

- Bullying, driving without the owner's permission, unattended driving, driving drunken, use of narcotics, etc. ${ }^{3}$

Usually, the worse the driver's history, the higher the correction factor and the premium. Within the proposed scale, the driver switched from one group to another, depending on the violetions or lack of such. To ensure equal treatment of the participants, the consultant's proposal is that everyone will get a neutral class at the start of the system.

Classes with a premium multiplier of less than $100 \%$ meet bonus classes, those with more than $100 \%$, of Malus classes. The neutral class, to which all persons are assigned at the start of the Bonus-Malus system, is the class with $100 \%$ premium multiplier.

\footnotetext{
${ }^{3}$ Preparation of the Bonus-Malus system (BMS) for Motor Third Party Liability insurance in Bulgaria, p. $12-13$
} 
ANDREEVA T.

\begin{tabular}{|c|c|c|c|c|c|c|c|}
\hline $\begin{array}{l}\text { Proposed rules for Bonus- } \\
\text { malus in Bulgaria }\end{array}$ & France & Hungary & Italy & Luxembourg & Roumenia & Latva & Holland \\
\hline $\begin{array}{l}\text { The claim history of the } \\
\text { owner is sed in the BM } \\
\text { classification. }\end{array}$ & $\mathbf{x}$ & $\mathbf{x}$ & $\checkmark$ & $\mathbf{x}$ & $\checkmark 1$ & $\checkmark$ & $\mathbf{x}$ \\
\hline $\begin{array}{l}\text { The claim history of the car } \\
\text { is used for BM } \\
\text { classification. }\end{array}$ & $\mathbf{x}$ & $\mathbf{x}$ & $\mathbf{x}$ & $\mathbf{x}$ & $\mathbf{x}$ & $\mathbf{x}$ & $\mathbf{x}$ \\
\hline $\begin{array}{l}\text { The BM classification of the } \\
\text { driver is affected. }\end{array}$ & $\checkmark$ & $\mathbf{x}$ & $\mathbf{x}$ & $\mathbf{x}$ & $\mathbf{x}$ & $\mathbf{x}$ & $\mathbf{x}$ \\
\hline $\begin{array}{l}\text { The most violent classification } \\
\text { of BM has to be chosen } \\
\text { between the claim of the owner } \\
\text { and the vehicle. }\end{array}$ & N/A & N/A & N/A & N/A & N/A & N/A & N/A \\
\hline $\begin{array}{l}\text { New BMS participants are } \\
\text { included in a neutral/ base } \\
\text { class }\end{array}$ & $\checkmark$ & $\checkmark$ & $\checkmark$ & $\checkmark$ & $\checkmark$ & $\checkmark$ & $\checkmark$ \\
\hline $\begin{array}{l}\text { When a person other than the } \\
\text { owner causes an accident, the } \\
\text { BM classification of the owner } \\
\text { will be affected, } \\
\text { as well as the driver. }\end{array}$ & $\mathbf{x}$ & $\mathbf{x}$ & $\mathbf{x}$ & $\mathbf{x}$ & $\mathbf{x}$ & $\mathbf{x}$ & $\mathbf{x}$ \\
\hline $\begin{array}{l}\text { During the transfer of ownership } \\
\text { of the vehicle a choise is made } \\
\text { between the riskier classification } \\
\text { of the BM of the vehicle and the } \\
\text { new owner. }\end{array}$ & $\mathbf{x}$ & $\mathbf{x}$ & $\mathbf{x}$ & $\mathbf{x}$ & $\mathbf{x}$ & $\mathbf{x}$ & $\mathbf{x}$ \\
\hline $\begin{array}{l}\text { For newly purchased vehicles } \\
\text { the BM classification of owner } \\
\text { is applied. }\end{array}$ & $\mathbf{x}$ & $\mathbf{x}$ & $\checkmark$ & $\mathbf{x}$ & $\checkmark$ & $\checkmark$ & $\mathbf{x}$ \\
\hline $\begin{array}{l}\text { For an individual who owns } \\
\text { more than one vehicle, the } \\
\text { more risk-based BM } \\
\text { classification between the } \\
\text { owner and the vehicle is } \\
\text { applied separately for each } \\
\text { vehicle. }\end{array}$ & N/A & N/A & N/A & N/A & N/A & N/A & N/A \\
\hline $\begin{array}{l}\text { For co-owned cars, the higher } \\
\text { risk rating of BM is applied } \\
\text { towards the owners. }\end{array}$ & $\mathbf{x}$ & $\mathbf{x}$ & $\checkmark$ & $\mathbf{x}$ & N/A & N/A & N/A \\
\hline $\begin{array}{l}\text { For vehicles owned by legal } \\
\text { entities, BM is classified on the } \\
\text { basis of the individual claims } \\
\text { history of each vehicle. }\end{array}$ & $\mathrm{x}$ & N/A & $\mathbf{x}$ & N/A & $\checkmark$ & $\mathbf{x}$ & N/A \\
\hline $\begin{array}{l}\text { The BM classification of the } \\
\text { driver will be chosen for leasing } \\
\text { cars. }\end{array}$ & $\checkmark$ & N/A & $\mathbf{x}$ & N/A & $\mathbf{x}$ & $\checkmark$ & N/A \\
\hline $\begin{array}{l}\text { In the case of a road accident } \\
\text { involving two or more vehicles } \\
\text { with equal responsibility, the } \\
\text { BM classification for each } \\
\text { owner and driver is affected. }\end{array}$ & $\checkmark$ & N/A & $\checkmark$ & N/A & N/A & $\checkmark$ & N/A \\
\hline $\begin{array}{l}\text { The owner's BM classification } \\
\text { will not be affected if the } \\
\text { vehicle is used without his } \\
\text { consent. }\end{array}$ & N/A & $\checkmark$ & N/A & N/A & $\checkmark$ & N/A & N/A \\
\hline $\begin{array}{l}\text { In the case of a pending court } \\
\text { case, the malus applies after a } \\
\text { decision has been made on the } \\
\text { responsible person. }\end{array}$ & $\mathbf{x}$ & $\checkmark$ & $\checkmark$ & $\checkmark$ & $\checkmark$ & $\checkmark$ & $\checkmark$ \\
\hline
\end{tabular}

Source: Preparation of the Bonus-Malus system (BMS) for Motor Third Party Liability insurance in Bulgaria

In the proposed Bonus-Malus system, the maximum discount of the premium is $29 \%$ and $40 \%$, while the largest possible increase is $400 \%$. With regard to premium multipliers, premium adjustments are not applied in a linear manner, and they depend on the person / vehicle Bonus-Malus classification before the occurrence of the road accident or violation. It follows that the higher the Bonus-Malus classification of the person before the incident, the greater the change in the premium multiplier. After the introduction of the system, Bulgarian insurance companies are expected to apply the premium multipliers to the respective bonus-malus class of the person, to the insurance premium of the person, calculated 
according to the company's classification policy. $^{4}$

After the introduction of the system, it may be assumed that corrections will need to be reflected on the basis of the observations from its application. It is appropriate to publicly report the results of the introduction of the system to the society for the purposes of its adoption and implementation. As key criteria factors that can be considered are: the development of the average damage by major types of claims, the frequency and severity of the essencial damages, changes in the premium level, others.

\section{CONCLUSION}

The Motor Third Party Liability insurance market in Bulgaria has been developing dynamically in recent years. The price of the insurance in 2018 marked a significant increase compared to previous years, when it was relatively constant and generally at low levels compared to the European market. From the review of the market development and FSC analysis of the results of the insurance on the market it can be concluded that an increase of the price of the product is necessary to cover the costs of the insurance. The measures that individual companies should take should be well predicted based on the development of risk in individual portfolios and segments. Under this insurance, the bonus-malus system should be implemented in market practice in the interests of society. The introduction of the system will favor a fair and punitive payment of an insurance premium and improved insurance performance. In order to reach the optimal solution, it will take time to adapt the initially implemented system.

\section{REFERENCES}

1. Report European insurance - Key Facts

2. Insurance code

3. Ordinance 49

4. Ordinance 53

5. Ordinance 54

6. Preparation of the Bonus-Malus system (BMS) for Motor Third Party Liability insurance in Bulgaria

7. Summary of the analysis of the market of compulsory Motor Third Party Liability insurance in Bulgaria (FSC report)

8. http://www.abz.bg/

9. http://www.guaranteefund.org/bg/

10.http://www.vks.bg/vks_p10_02_6.htm

11.http://www.fsc.bg/bg/

12.Bates, I., Athins, D., Management of insurance operations, 2-nd edition, Global professional publishing, London, 2007

13. Gonulal, S. O. Motor Third party liability insurance in developing coutries, Washington, 2009

14. Vaughan, Th., Vaughan, E., Fundamentals of risk and insurance, 10-th edition, JohnWiley \& Sons, USA, 2008

\footnotetext{
${ }^{4}$ Preparation of the Bonus-Malus system (BMS)

for Motor Third Party Liability insurance in Bulgaria, p. $14-16$
} 